\title{
Role of Ultrasound in the Diagnosis and Differentiation between Inflammatory and Cystic Swellings of Head and Neck Region
}

\author{
${ }^{1}$ Rakhi M Chandak, ${ }^{2}$ Manoj G Chandak, ${ }^{3}$ Shivlal M Rawlani
}

\begin{abstract}
Ultrasound means the form of sound energy beyond the audible range. Ultrasonography (USG) is a safe and reliable method of examination that causes little patient discomfort and provides valuable information concerning size, location, internal nature of soft tissue masses in oral and neck lesion. Ultrasound is capable of differentiating cystic from solid lesions.

The aim of this study was to compare the ultrasonographic differentiation of inflammatory swelling and cystic swelling with each other in head and neck regions. Intergroup comparison was also carried out in the study.

For this single-blind cross-sectional study, 45 cases with clinically obvious swelling in head and neck region were selected randomly. Following clinical and ultrasonographic diagnosis and appropriate further investigations, surgical intervention was carried out.

After considering the results of all 45 cases of the present study, it can be concluded that clinical diagnosis had a sensitivity and accuracy of $85.71 \%$, whereas ultrasonographic diagnosis had a sensitivity and accuracy of $98.57 \%$.
\end{abstract}

Keywords: Accuracy, Cystic swelling, Inflammatory swelling, Intergroup comparison, Sensitivity, Ultrasound.

How to cite this article: ChandakRM, ChandakMG, Rawlani SM. Role of Ultrasound in the Diagnosis and Differentiation between Inflammatory and Cystic Swellings of Head and Neck Region. J Contemp Dent 2016;6(2):117-124.

Source of support: Nil

Conflict of interest: None

\section{INTRODUCTION}

Ultrasound means the form of sound energy beyond the audible range. Just as an eye can see only limited range of frequencies of electromagnetic spectrum, i.e.,

\footnotetext{
${ }^{1}$ Senior Lecturer, ${ }^{2}$ Professor and Head, ${ }^{3}$ Reader

${ }^{1}$ Department of Oral Medicine and Radiology, Swargiya Dadasaheb Kalmegh Smruti Dental College \& Hospital, Nagpur Maharashtra, India

2Department of Conservative Dentistry, Sharad Pawar Dental College, Nagpur, Maharashtra, India

${ }^{3}$ Department of Oral Medicine and Radiology, Sharad Pawar Dental College, Nagpur, Maharashtra, India

Corresponding Author: Rakhi M Chandak, Senior Lecturer Department of Oral Medicine and Radiology, Swargiya Dadasaheb Kalmegh Smruti Dental College \& Hospital Nagpur, Maharashtra, India, Phone: +917122432568, e-mail: rakhirakhi76@gmail.com
}

visible light, ear can hear only limited range of sound frequencies, i.e., 20 to $20000 \mathrm{~Hz}$. Beyond the audible range, there are sounds which cannot be heard. Sound with frequency below the audible range is called as infrasonic and frequency above the audible limit is ultrasonic. Ultrasound used for diagnostic purposes has frequency of 2 to $20 \mathrm{MHz}^{1,2}$

Diagnostic ultrasound utilizes transducer that generate narrow focus beam. This beam is reflected from the tissue examined back to the same transducer which assembles these echoes into an image that can be visualized and recorded. There are various modes in ultrasound, such as:

- A mode: It measures intensity of echo in terms of its height on graph scale with $X$ and $Y$ axis.

- B mode: In B mode echoes are displayed as bright dots and brightness is proportional to the intensity of echo. ${ }^{3}$

Ultrasonography (USG) has become modality of choice because of its ease of use, and it is superior for detecting tumorous lesions and describes structure and vascularity of lesion. When compared with fine-needle aspiration biopsy, USG is not associated with damage to facial nerve branches. ${ }^{4}$

Sonography is an inexpensive and noninvasive diagnostic technique with high sensitivity and specificity that can be used in the diagnosis of inflammatory soft tissue swelling of oral and maxillofacial region as well as neck. It can also be used to help locate abscess cavities and thereby give hints for surgical approach. B scan sonography is also used regularly to follow the course of disease and its response to nonsurgical treatment. ${ }^{5}$

Ultrasonography is a safe and reliable method of examination that causes little patient discomfort and provides valuable information concerning size, location, internal nature of soft tissue masses in oral and neck lesion. Ultrasound is capable of differentiating cystic from solid lesions. ${ }^{6}$

Ultrasound is a nonelectromagnetic, noninvasive, cost-effective, cost affordable, and nonionizing radiation that can be used to image the internal structures and also has wide clinical application. It has become popular among clinicians and patients. ${ }^{1}$ 
Various disease processes may affect head and neck region, which has clinical presentation as well as swellings in this region. The disease processes that lead to such types of swellings are broadly considered as an inflammatory, cystic, benign, or malignant in nature.

Although patient's detailed case history and clinical examination are the most important and mandatory steps in the evaluation of any swelling, it may not carry $100 \%$ sensitivity and accuracy in the diagnosis.

Hence in the present study, an attempt has been made to evaluate the role of USG in the process of arriving at the diagnosis of swelling in the head and neck region, with a special emphasis on comparison of its sensitivity and accuracy with clinical diagnosis.

The aim of this study was to compare the ultrasonographic differentiation of inflammatory swelling and cystic swelling with each other in head and neck regions. Intergroup comparison was also carried out in the study.

\section{MATERIALS AND METHODS}

For this single-blind cross-sectional study, 45 cases with clinically obvious swelling in head and neck region were selected randomly in the age range of 8 to 50 years and male to female ratio was 3:2.

The protocol of this study was approved by Institutional Ethical Committee of Datta Meghe Institute of Medical Sciences University, Sawangi (Meghe), Wardha. The patient's detailed case history was taken and clinical examination was done based on the criteria given by Das.? The data obtained was recorded in structured proforma and a provisional diagnosis was made and recorded in proforma.

On the basis of the clinical diagnosis, swellings were divided into two groups: Inflammatory swelling and cystic swelling. Inclusion criteria for this study are swellings due to soft tissue lesions of head and neck regions and exclusion criteria are those swellings due to trauma or fracture, and swellings obscured by overlying jaw bone were not included. After that, ultrasonographic investigation of each swelling was carried out using Philips Envisors C Series of ultrasonogram with linear transducer probe at a frequency of $15 \mathrm{MHz}$ with a depth of $3 \mathrm{~cm}$ and is used when the lesion is $<3.5 \mathrm{~cm}$ in diameter. Whereas transcavitary probe at a frequency of $7.5 \mathrm{MHz}$ with a depth of $8 \mathrm{~cm}$ is used when the lesion is larger than $3.5 \mathrm{~cm}$ in diameter. Experienced and qualified sonologist who was unaware of clinical data in any case performed ultrasonographic examination.

The following features were considered in describing the ultrasonographic images of swelling in head and heck in accordance with Shimizu et $\mathrm{al}^{4}$ :

- Shape: Oval, lobular, round, polygonal, irregular

- Boundary: Very clear, relatively clear, partially unclear, and ill-defined
- Echo intensity: Anechoic, isoechoic, hypoechoic, hyperechoic, and mixed (isoechoic + hyperechoic/ hypoechoic)

- Ultrasound architecture of lesion: Homogenous, heterogenous

- Presence of necrosis, presence of calcification

- Posterior echoes: Enhanced, unchanged, attenuated

- Ultrasound characteristic of tissues: Cystic, solid, mixed.

The following clinical and ultrasonographic diagnosis and appropriate further investigations and surgical intervention were carried out by incision and drainage or excision/incisional biopsy/FNAC as indicated. The obtained biopsy specimens were submitted for histopathological examination and final diagnosis was made and recorded in prescribed proforma. The clinical data thereafter was correlated with ultrasonographic findings. After that, both the clinical and ultrasonographic findings were correlated with final diagnosis and were subjected to statistical evaluation.

The obtained results were tabulated and statistically analyzed by considering the final diagnosis. Sensitivity, specificity, positive predictive value, negative predictive value, and accuracy of test were calculated to evaluate reliability and diagnostic efficacy of USG as an investigative tool.

\begin{tabular}{ll}
\hline Disease & No disease \\
\hline A & B \\
True - positive & False- positive \\
C & D \\
False - negative & True - negative \\
\hline
\end{tabular}

Sensitivity $=\frac{A}{A+C} \times 100$

Sensitivity $=\frac{D}{B+D} \times 100$

Positive predictive value $=\frac{A}{A+B} \times 100$

Negative predictive value $=\frac{D}{C+D} \times 100$

Accuracy $=\frac{A+D}{N} \times 100$

Where $\mathrm{N}=$ number of patients (45).

Z-test was calculated for difference between two proportions

$Z=\frac{P_{1}-P_{2} N}{\sqrt{\frac{P_{1} q_{1}}{n_{1}}+\frac{P_{2} q_{2}}{n_{2}}}}$

$\mathrm{P}_{1}=$ Proportion of positive values in first test

$\mathrm{P}_{2}=$ Proportion of positive values in second test

$\mathrm{q}_{1}=1-\mathrm{P}_{1}$

$\mathrm{q}_{2}=1-\mathrm{P}_{2}$ 
If $\mathrm{Z} \geq 1.96$, then it is considered as significant, and if the value is greater than 4 then it is considered as highly significant.

\section{RESULTS}

A total of 45 cases with clinically obvious swellings in head and neck region were included in the study and were broadly classified into two groups (Table 1):

- $35(77.77 \%)$ were inflammatory swellings

- $10(22.22 \%)$ were cystic swellings.

\section{Inflammatory Swelling}

Out of the total 35 swellings, 30 swellings finally diagnosed as inflammatory swellings were having clinical signs of inflammation.

Table 1: Spectrum of disease processes in the study of head and neck swellings

\begin{tabular}{llll}
\hline Sl. no. & Diseases & No. of patients & Percentage \\
\hline 1 & Inflammatory swellings & 35 & 77.77 \\
2 & Cystic swellings & 10 & 22.22 \\
\hline & Total & 45 & 100 \\
\hline
\end{tabular}

Inflammatory swellings that showed signs of inflammation are either odontogenic in origin (18 out of 30), which were diagnosed as cellulitis or abscess, or nonodontogenic in origin (Figs 1A and B) (12 out of 30). Out of these 12 inflammatory swellings of nonodontogenic in origin, 5 were diagnosed as sialadenitis (Figs 2A and B) as they originated from salivary gland and the remaining 7 were inflammatory swellings of lymph node origin, hence were diagnosed as reactive or nonspecific lymphadenitis. Clinical diagnosis of all these cases was done after eliciting thorough history and detailed clinical examination.

In five patients, clinical diagnosis did not match with final diagnosis and in one case sonographic diagnosis did not match with final diagnosis. In one case, clinical diagnosis was dermoid cyst whereas on ultrasound, it appeared as inflammatory lesion and final diagnosis was infected foreign body granuloma. In second case, clinical diagnosis was submandibular lymphadenopathy whereas ultrasound diagnosis and final diagnosis was obstructive submandibular sialadenitis due to sialolithiasis. In third case, clinical diagnosis was chronic periapical abscess whereas ultrasound diagnosis and final diagnosis was submandibular lymphadenitis. In fourth case,
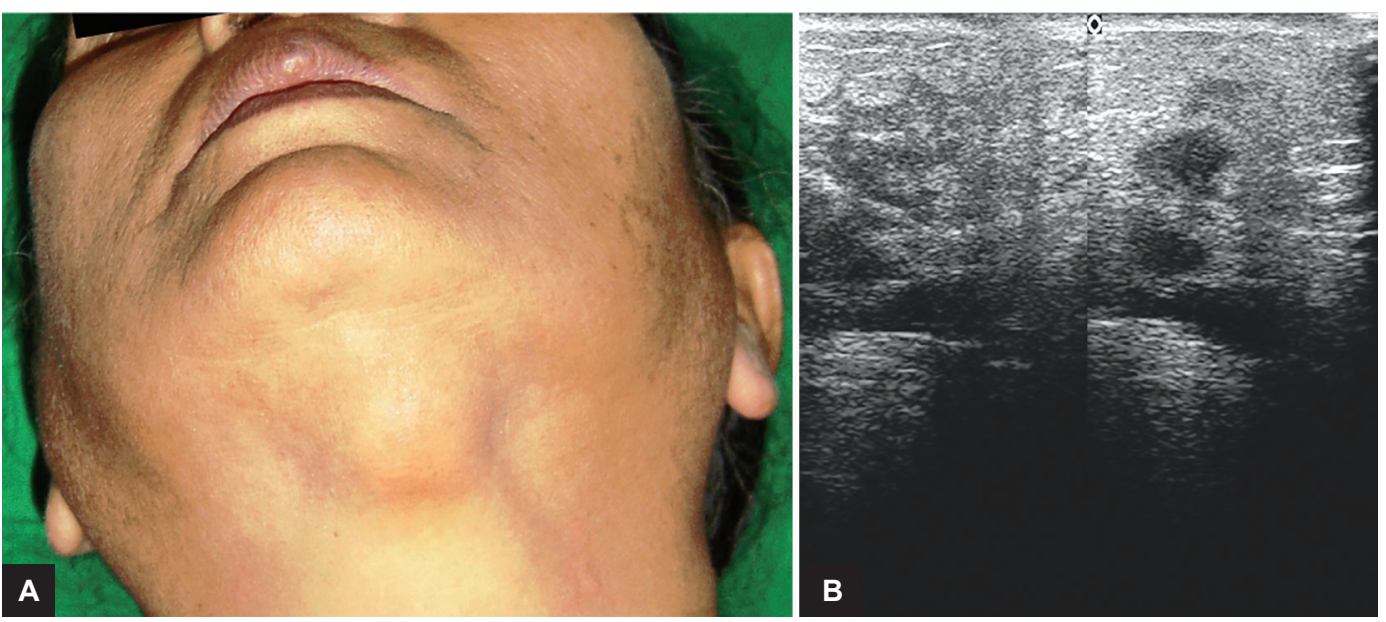

Figs 1A and B: (A) Clinical extraoral photograph of swelling in submental region; and (B) ultrasonographic image shows inhomogenous mixed echogenic lesion with relatively clear borders suggestive of inflammatory lesion
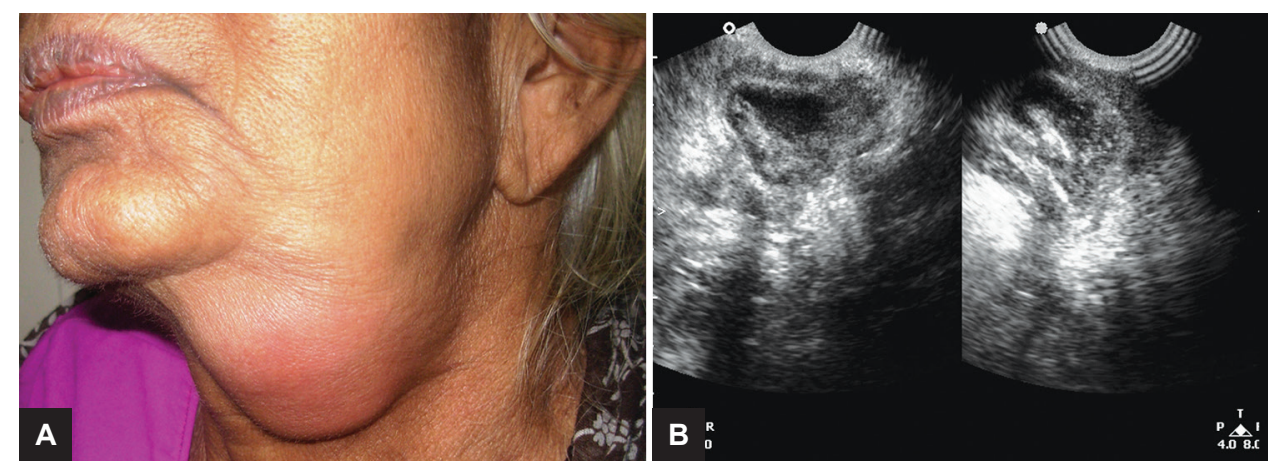

Figs 2A and B: (A) Clinical extraoral photograph of swelling in submandibular region on right side; and (B) ultrasonographic image shows submandibular gland enlargement with well-defined hypoechoic lesion within it suggestive of inflammatory evolving abscess 


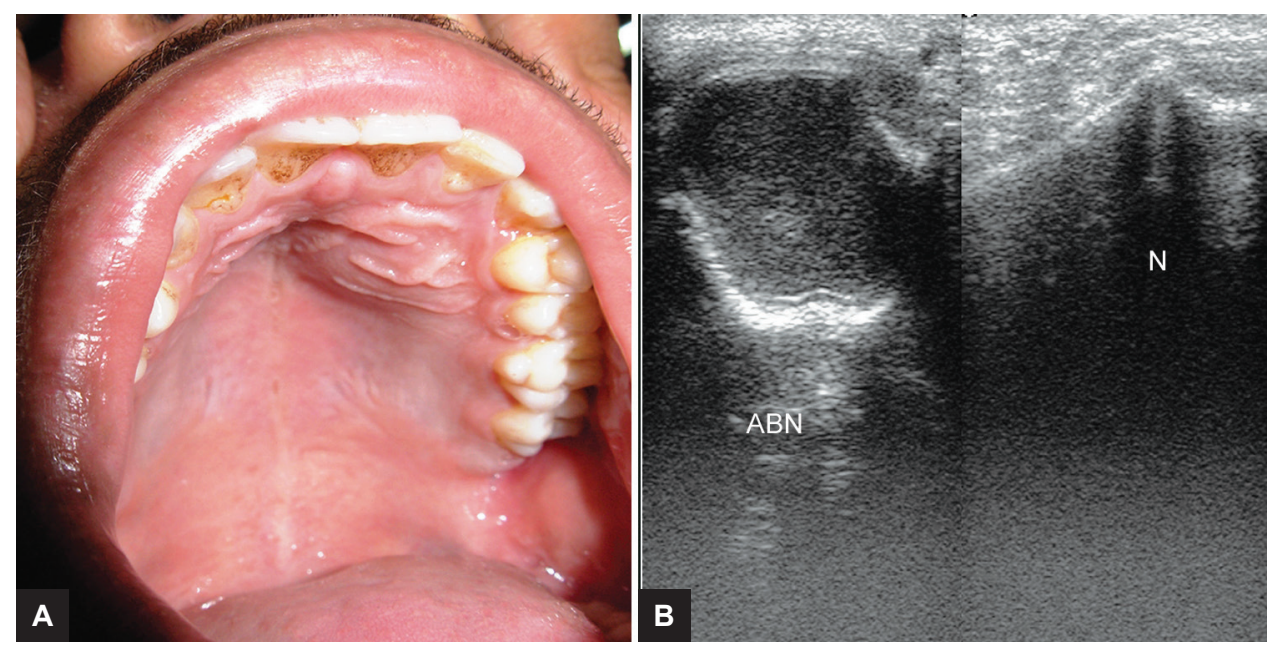

Figs $3 A$ and B: (A) Clinical extraoral photograph of swelling in palates s/o infected dental cyst; and (B) well-defined cystic lesion with eccentric hyperechoic tiny nodules s/o cysticercosis cellulosae with adjacent perilesional edema

clinical diagnosis was fibroma of cheek whereas ultrasound diagnosis was hematoma in masseter muscle and final diagnosis was cysticercosis cellulosae. In fifth case, clinical diagnosis was submandibular lymphadenopathy whereas ultrasound diagnosis and final diagnosis was cysticercosis cellulosae.

\section{Cystic Swelling}

Out of the total 10 swellings, 8 swellings diagnosed as cystic swellings were having clinical signs of cysts. Cysts of odontogenic origin were six (Figs 3A and B) and cysts of nonodontogenic origins were two in number.

In 2 patients out of 10, clinical diagnosis did not match with final diagnosis whereas all the sonographic diagnosis did match with final diagnosis. In first case; clinical diagnosis was fibroma whereas ultrasound and final diagnosis was sebaceous cyst. In second case, clinical diagnosis was lip abscess whereas ultrasound diagnosis was cystic lesion and final diagnosis was mucus retention cyst.

In Table 2, ultrasonographic features of inflammatory swellings are given and from this table we noted that inflammatory swellings had relatively clear boundary in $51.43 \%$ of cases, very clear in $34.29 \%$, and ill-defined in $14.29 \%$ of cases. Shapes of inflammatory swellings were irregular in $42.86 \%$ of cases, lobular in $8.57 \%$ of cases, oval in $37.14 \%$ of cases, and round in $11.43 \%$ of cases. Echo intensity of inflammatory swellings was anechoic in $31.43 \%$ of cases, hypoechoic in $42.86 \%$ of cases, hypo+hyperechoic in $8.57 \%$ of cases, and isoechoic in $17.14 \%$ of cases. Ultrasound architecture of lesions of inflammatory swellings was homogenous in $65.71 \%$ of cases and heterogenous in $34.29 \%$ of cases. Posterior echoes of inflammatory swellings were enhanced in $48.57 \%$ of cases, attenuated in $14.29 \%$ of cases, unchanged in $34.29 \%$ of cases, and unenhanced in $2.86 \%$ of cases.
Table 2: Ultrasonographic features of inflammatory swellings - total (35)

\begin{tabular}{llll}
\hline Gray scale & Inflammatory & & \\
sonographic feature & swellings & No. & Percentage \\
\hline Boundary & Very clear & 12 & 34.29 \\
& Relatively clear & 18 & 51.43 \\
& Partially unclear & - & - \\
& Ill-defined & 5 & 14.29 \\
Shape & Oval & 13 & 37.14 \\
& Lobular & 3 & 8.57 \\
& Polygonal & - & - \\
& Irregular & 15 & 42.86 \\
Echo intensity & Round & 4 & 11.43 \\
& Anechoic & 11 & 31.43 \\
& Isoechoic & 6 & 17.14 \\
Ultrasound & Hypoechoic & 15 & 42.86 \\
architecture of lesion & Hyperechoic & - & - \\
Posterior echoes & Hixed (hypo +hyper) & 3 & 8.57 \\
& Heterogenous & 23 & 65.71 \\
& Enhanced & 12 & 34.29 \\
& Unchanged & 12 & 48.57 \\
Ultrasound & Attenuated & 5 & 14.29 \\
characteristic of & Unenhancement & 1 & 2.86 \\
tissues & Cystic & 15 & 42.86 \\
\hline & Solid & 16 & 45.71 \\
& Mixed & 4 & 11.43 \\
\hline & & &
\end{tabular}

Ultrasound characteristics of tissues of inflammatory swellings were cystic in $42.86 \%$ of cases, solid in $45.71 \%$, and mixed in $11.43 \%$ of cases.

From this table it can be concluded that most of the inflammatory swellings had relatively clear boundary, irregular in shape, hypoechoic in echo intensity, homogenous in ultrasound architecture of lesion, posterior echoes were enhanced, and ultrasound characteristics of tissues were cystic or solid in nature.

In Table 3, ultrasonographic features of cystic swellings are given and from this table we noted that all of 
Role of Ultrasound in the Diagnosis and Differentiation between Inflammatory and Cystic Swellings

Table 3: Ultrasonographic features of cystic swellings - total (10)

\begin{tabular}{|c|c|c|c|}
\hline $\begin{array}{l}\text { Gray scale } \\
\text { sonographic feature }\end{array}$ & Cystic swellings & No. & Percentage \\
\hline Boundary & $\begin{array}{l}\text { Very clear } \\
\text { Relatively clear } \\
\text { Partially unclear } \\
\text { Ill-defined }\end{array}$ & 10 & 100 \\
\hline Shape & $\begin{array}{l}\text { Oval } \\
\text { Lobular } \\
\text { Polygonal } \\
\text { Irregular }\end{array}$ & 3 & 37.5 \\
\hline & $\begin{array}{l}\text { Round } \\
\text { Tubular }\end{array}$ & $\begin{array}{l}6 \\
1\end{array}$ & \\
\hline Echo intensity & $\begin{array}{l}\text { Anechoic } \\
\text { Isoechoic }\end{array}$ & 9 & 87.5 \\
\hline & $\begin{array}{l}\text { Hypo + anechoic } \\
\text { Hyperechoic }\end{array}$ & 1 & 12.5 \\
\hline $\begin{array}{l}\text { Ultrasound } \\
\text { architecture of lesions }\end{array}$ & $\begin{array}{l}\text { Homogenous } \\
\text { Heterogenous }\end{array}$ & $\begin{array}{l}9 \\
1\end{array}$ & $\begin{array}{l}87.5 \\
12.5\end{array}$ \\
\hline Posterior echo & $\begin{array}{l}\text { Enhanced } \\
\text { Unchanged } \\
\text { Attenuated }\end{array}$ & 10 & 100 \\
\hline $\begin{array}{l}\text { Ultrasound } \\
\text { characteristic } \\
\text { of tissues }\end{array}$ & $\begin{array}{l}\text { Cystic } \\
\text { Solid } \\
\text { Mixed }\end{array}$ & 10 & 100 \\
\hline
\end{tabular}

cystic swellings had very clear boundary in $100 \%$ of cases. Shapes of cystic swellings were round in $50 \%$ of cases, oval in $37.5 \%$ of cases, and tubular in $12.5 \%$ of cases. Echo intensity of cystic swellings was anechoic in $87.5 \%$ of cases; hypo+anechoic in $12.5 \%$ of cases. Ultrasound architecture of lesions of cystic swellings was homogenous in $87.5 \%$ of cases and heterogeneous in $12.5 \%$ of cases. Posterior echo of cystic swellings was enhanced in $100 \%$ of cases. Ultrasound characteristic of tissues of cystic swellings was cystic in $100 \%$ of cases.

From this table it can be concluded that most of cystic swellings had very clear boundary, round in shape, echo intensity of cystic swellings was anechoic, ultrasound architecture of lesions of cystic swellings was homogenous, posterior echo was enhanced, and ultrasound characteristic of tissues of cystic swellings was cystic.

For the intergroup comparison among the two groups of swellings, one group for the comparison was made, such as inflammatory swellings from cystic swellings.

Tables 4 to 9 show the comparison of inflammatory swellings and cystic swellings in head and neck according to gray scale sonographic features. In these tables, the criteria taken for the comparison are boundary, shape, echo intensity, ultrasound architecture of lesion, posterior echo, and ultrasound characteristic of tissues.

From Tables 4 to 9, it can be concluded that in gray scale USG, the criteria of boundary, shape, echo intensity, posterior echo, and ultrasound characteristic of tissues
Table 4: Comparison of boundary of inflammatory swellings and cystic swellings in head and neck according to gray scale sonographic feature

\begin{tabular}{lll}
\hline Gray scale sonographic feature & Inflammatory & Cystic \\
\hline Very clear & $12(34.29 \%)$ & $10(100 \%)$ \\
III-defined & $5(14.29 \%)$ & - \\
Relatively clear & $18(51.43 \%)$ & - \\
Partially unclear & - & - \\
\hline Total & 35 & 10 \\
\hline$\chi^{2}$ Calculated value for boundary & $11.30 ; p$-value $=0.003 ;$ \\
result: significant, $p<0.05$
\end{tabular}

Table 5: Comparison of shapes of inflammatory swellings and cystic swellings in head and neck according to gray scale sonographic feature

\begin{tabular}{lll}
\hline Gray scale sonographic feature & Inflammatory & Cystic \\
\hline Oval & $13(37.14 \%)$ & $3(37.5 \%)$ \\
Round & $4(11.43 \%)$ & $6(50 \%)$ \\
Irregular & $15(42.86 \%)$ & - \\
Lobular & $3(8.57 \%)$ & $1(12.5 \%)$ \\
\hline Total & 35 & 10 \\
\hline$\chi^{2}$ Calculated value for shapes $=8.74 ; p$-value $=0.03 ;$ & result: \\
significant, $p<0.05$ &
\end{tabular}

Table 6: Comparison of echo intensity of inflammatory swellings and cystic swellings in head and neck according to gray scale sonographic feature

\begin{tabular}{lll}
\hline Gray scale sonographic feature & Inflammatory & Cystic \\
\hline Anechoic & $11(31.43 \%)$ & $9(87.5 \%)$ \\
Isoechoic & $6(17.14 \%)$ & - \\
Hypoechoic & $18(51.43 \%)$ & $1(12.5 \%)$ \\
Hyperechoic & - & - \\
\hline Total & 35 & 10 \\
\hline
\end{tabular}

$\chi^{2}$ Calculated value for echo intensity $=8.49 ; p$-value $=0.01$; result: significant, $p<0.05$

Table 7: Comparison of ultrasound architecture of lesion of inflammatory swellings and cystic swellings in head and neck according to gray scale sonographic feature

\begin{tabular}{lll}
\hline Gray scale sonographic feature & Inflammatory & Cystic \\
\hline Homogenous & $23(65.71 \%)$ & $9(87.5 \%)$ \\
Heterogenous & $12(34.29 \%)$ & $1(12.5 \%)$ \\
\hline Total & 35 & 10
\end{tabular}

$\chi^{2}$ Calculated value for ultrasound architecture of lesion $=1.46$; $p$-value $=0.22$; result: not significant, $p>0.05$

are statistically significant to differentiate inflammatory swellings from cystic swellings in head and neck as the $\mathrm{p}$-value is $<0.05$.

In Table 10, the p value is calculated for differentiation of inflammatory swellings from cystic swellings by using USG and it is statistically not significant as the $p$-value is $>0.05$. In cases of inflammatory swellings, 34 cases were diagnosed positively on USG and one case had negative findings and in cases of cystic swellings, all eight cases were diagnosed positively on USG and no negative findings were seen. The p-value is statistically not significant. 
Table 8: Comparison of posterior echoes of inflammatory swellings and cystic swellings in head and neck according to gray scale sonographic feature

\begin{tabular}{lll}
\hline Gray scale sonographic feature & Inflammatory & Cystic \\
\hline Enhanced & $18(51.43 \%)$ & $10(100 \%)$ \\
Unchanged & $12(34.29 \%)$ & - \\
Attenuated & $5(14.29 \%)$ & - \\
\hline Total & 35 & 10
\end{tabular}

$\chi^{2}$ Calculated value for posterior echoes $=6.42 ; p$-value $=0.04$; result: significant, $p<0.05$

Table 10: Evaluation of $p$ value of USG in differentiation of inflammatory swellings from cystic swellings

\begin{tabular}{lll}
\hline Swellings & Positive & Negative \\
\hline Inflammatory & 34 & 1 \\
Cystic & 10 & 0 \\
$\chi^{2}$-value & \multicolumn{2}{c}{0.23} \\
Significance & \multicolumn{2}{c}{ Not significant, $p>0.05$} \\
\hline
\end{tabular}

In Table 11, the $Z$ value is calculated for differentiation of cellulitis from abscess by using USG and it is statistically significant as the $Z$ value is 2.58 . In cases of cellulitis all 4 cases were diagnosed positively and no negative findings were seen and in cases of abscesses all 14 cases were diagnosed positively and no negative findings were seen, so the $Z$ value is statistically significant.

Graph 1 shows the comparison of each individual criterion of gray scale USG in inflammatory swellings and cystic swellings. In this table, sensitivity, specificity, positive predictive value, negative predictive value, and accuracy of test of each individual criterion of gray scale USG in inflammatory swellings and cystic swellings are shown.

Graph 2 shows the comparison of clinical and ultrasonographic diagnosis of inflammatory swellings. In this table, sensitivity, specificity, positive predictive value, negative predictive value, and accuracy of test in

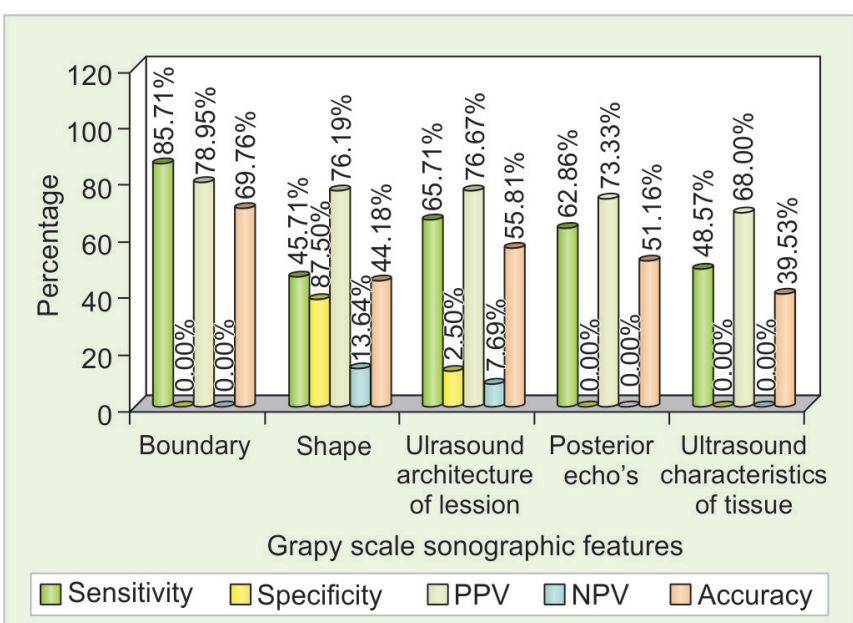

Graph 1: Comparison of each individual criterion of gray scale USG in inflammatory swellings and cystic swellings
Table 9: Comparison of ultrasound characteristic of tissues of inflammatory swellings and cystic swellings in head and neck according to gray scale sonographic feature

\begin{tabular}{lll}
\hline Gray scale sonographic feature & Inflammatory & Cystic \\
\hline Cystic & $15(42.86 \%)$ & $10(100 \%)$ \\
Solid & $16(45.71 \%)$ & - \\
Mixed & $4(11.43 \%)$ & - \\
\hline Total & 35 & 10 \\
\hline$\chi^{2}$ Calculated value for ultrasound characteristic of tissues $=8.54 ;$ \\
p-value $=0.01 ;$ result: significant, $p<0.05$
\end{tabular}

Table 11: Evaluation of $Z$ value of USG in differentiation of cellulitis from abscesses

\begin{tabular}{llll}
\hline Swellings & Positive & Negative \\
\hline Cellulitis & 4 & & 0 \\
Abscesses & 14 & 0 \\
Z-value & \multicolumn{2}{c}{$\begin{array}{l}2.58 \\
\text { Significance }\end{array}$} & Significant \\
\hline
\end{tabular}

inflammatory swellings are shown. Clinical diagnosis had a sensitivity of $85.71 \%$, specificity of $85.71 \%$, positive predictive value is $85.71 \%$, negative predictive value is $85.71 \%$, and accuracy of test is $85.71 \%$ whereas sonographic diagnosis had a sensitivity of $97.14 \%$, specificity $100 \%$, positive predictive value is $100 \%$, negative predictive value is $97.22 \%$, and accuracy of test is $98.57 \%$.

Graph 3 shows the comparison of clinical and ultrasonographic diagnosis of cystic swellings. In this table, sensitivity, specificity, positive predictive value, negative predictive value, and accuracy of test in cystic swellings are shown. Clinical diagnosis had a sensitivity of $75.00 \%$, specificity of $87.10 \%$, positive predictive value is $42.86 \%$, negative predictive value is $96.43 \%$ and accuracy of test is $85.71 \%$ whereas sonographic diagnosis had a sensitivity of $100 \%$, specificity $98.39 \%$, positive predictive value is $88.89 \%$, negative predictive value is $100 \%$, and accuracy of test is $98.57 \%$.

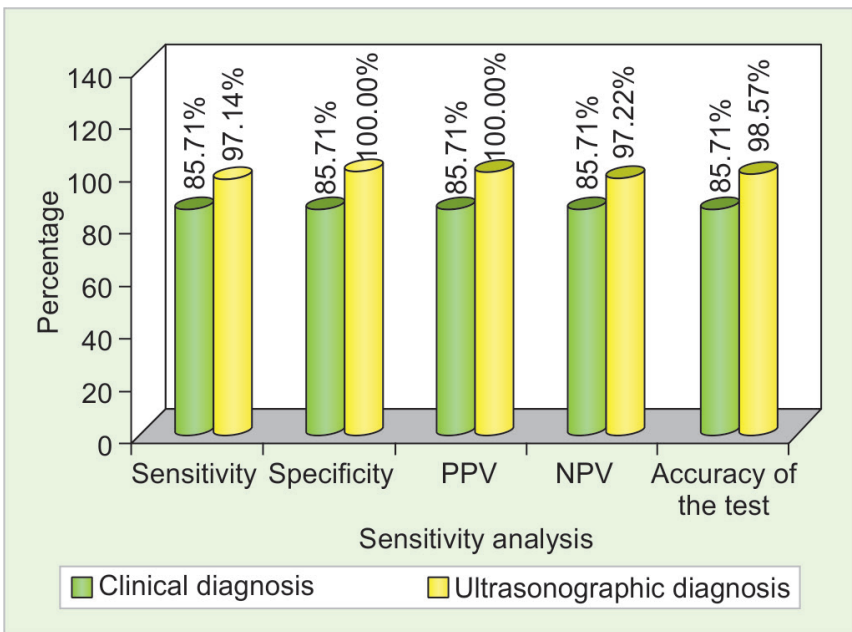

Graph 2: Comparison of clinical and ultrasonographic diagnosis of inflammatory swellings 


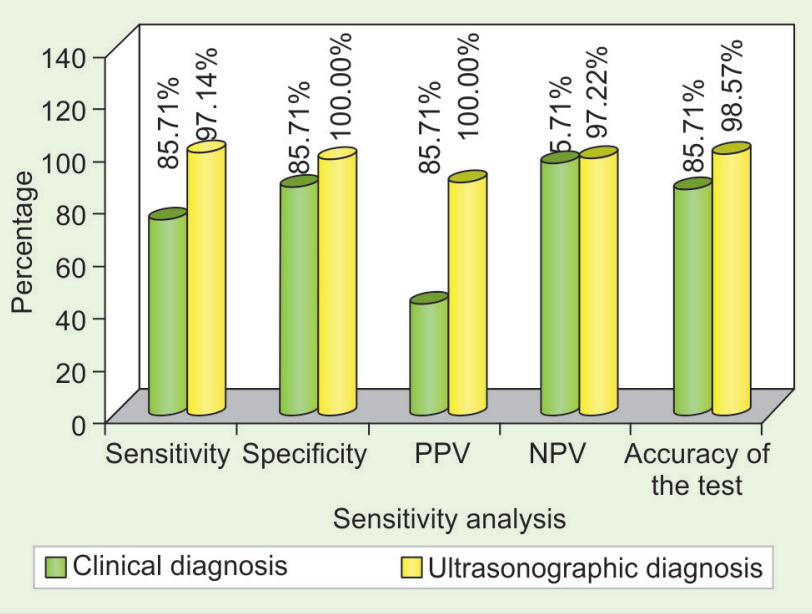

Graph 3: Comparison of clinical and ultrasonographic diagnosis of cystic swellings

After considering the results of all 45 cases of the present study, it can be concluded that clinical diagnosis had a sensitivity and accuracy of $85.71 \%$ whereas ultrasonographic diagnosis had a sensitivity and accuracy of $98.57 \%$.

\section{DISCUSSION}

Ultrasonography is a noninvasive, relatively economical procedure and can be applied easily and repeatedly. It has become an important tool in the diagnosis and management of maxillofacial diseases. ${ }^{8}$

In the present study, out of finally diagnosed 35 cases of inflammatory swellings, 30 cases were clinically diagnosed as inflammatory, out of which, 18 cases had odontogenic in origin. Out of these 18 cases, 4 cases had cellulitis and 14 cases were having abscesses diagnosed ultrasonographically.

From this study, it can be concluded that most of inflammatory swellings had relatively clear boundary, irregular in shape, hypoechoic in echo intensity, homogenous in ultrasound architecture of lesion, posterior echoes were enhanced, and ultrasound characteristic of tissues was cystic or solid in nature. Our findings were correlated with the findings of Sivarajasingam et $\mathrm{al}^{9}$ and Baurmash, ${ }^{10}$ who stated that in cases of abscesses, USG showed reduction of echo intensity and deep "underlying cystic change."

In this study, out of six cases, three cases had coarsening of glandular parenchyma and hypoechoic areas and had heterogenous echotexture of gland, as seen in parotitis and submandibular sialadenitis. Our findings were correlated with the findings given by Howlett, ${ }^{11}$ Alyas et al, ${ }^{12}$ and Howlett et al. ${ }^{13}$

In the present study, in one case which was diagnosed clinically as submandibular lymphadenopathy, the ultrasound showed hyperechoic foci casting posterior acoustic shadowing and also assessed enlargement of gland. Duct dilation proximal to obstruction was also seen and was diagnosed as submandibular sialolith resulting in obstructive sialadenitis. These findings were consistent with the findings given by Traxler et al, ${ }^{14}$ Schemelzeisen et al, ${ }^{15}$ and Yoshimura et al. ${ }^{16}$

Out of 35 cases, 8 were inflammatory swellings of lymph node origin, which were diagnosed as reactive or nonspecific lymphadenitis, out of which 7 were clinically suspected to be reactive or nonspecific cervical lymphadenitis.

In the present study, in a group of inflammatory swellings, clinical diagnosis had a sensitivity and specificity of $85.71 \%$, whereas sonographic diagnosis had a sensitivity of $97.14 \%$ and specificity of $100 \%$.

In this study, all 10 cases of cystic swellings had very clear boundary. Echo intensity of cystic swelling was anechoic. Ultrasound architecture of lesions of cystic swellings was homogenous. Posterior echo of cystic swellings was enhanced and ultrasound characteristic of tissues of cystic swelling was cystic. Our findings were in complete correlation with the findings given by El-Silimy and Corney ${ }^{17}$ and Ishikawa et al. ${ }^{6}$

In the present study, in a group of cystic swellings, clinical diagnosis had a sensitivity of $75 \%$, specificity of $87.10 \%$, whereas sonographic diagnosis had a sensitivity of $100 \%$ and specificity of $98.39 \%$.

In the present study, comparisons of cases of clinical, ultrasonographic, and final diagnosis in head and neck swellings have shown that in disease process of inflammatory swellings, out of 35 cases, clinical diagnosis in 30 cases was true positive and in 5 cases was false negative whereas sonographic diagnosis was true positive in 34 cases and false negative only in 1 case.

In disease process of cystic swellings, out of 10 cases, in 8 cases clinical diagnosis was true positive and in 2 cases was false negative, whereas all the sonographic diagnosis did match with final diagnosis, so all the cases are true positive in USG.

For the intergroup comparison among the two groups of swellings, one group for the comparison was made, such as inflammatory swellings from cystic swellings. Comparison has been made between inflammatory swellings and cystic swellings in head and neck according to gray scale sonographic features, and the criteria of boundary, shape, echo intensity, posterior echo's and ultrasound characteristic of tissue are statistically significant to differentiate inflammatory swellings from cystic swellings and also by using chi-square test, the $p$ value is calculated for differentiation of inflammatory swellings from cystic swellings by using USG and it is statistically not significant as the $\mathrm{p}$-value is $>0.05$.

From the present study, it can be concluded that USG is an important diagnostic tool for swellings of head and 
neck and the technique is also noninvasive, safe, and inexpensive. In the present study, ultrasonographic pictures were consistent and did correspond with great degree of accuracy in all the group of lesions. Though USG has been found to be definitely superior to clinical examination in head and neck swellings but importance of initial clinical evaluation of swellings cannot be overemphasized.

The purpose of USG as one of modality of investigation is not to provide alternative to the procedure of clinical examination in the diagnosis of head and neck swellings but its purpose is to get more information about swellings which may add or support the outcomes of findings of clinical examination. And in the process of clinical evaluation there is always likelihood of difference in the diagnostic opinion about few clinically false negative cases which requires confirmation by other modalities leadings to final diagnosis which will help patient and clinician for adopting proper therapeutic approach.

\section{CONCLUSION}

It can be summarized that after clinical examination, ultrasound should be the first modality used for the investigation as it is readily available and does not involve ionizing radiation, after which $\mathrm{CT}$ and MRI can be used to determine the extent of mass and to better define its tissue characteristics. It is also recommended that USG be routinely performed as a part of evaluation of all patients with head and neck swellings.

- From the present study, in cases of inflammatory swellings and cystic swellings, ultrasonographic criteria of boundary, shape, echo intensity, posterior echoes, and ultrasound characteristic of tissue are statistically significant criteria to differentiate inflammatory swellings from cystic swellings as $p$-value is $<0.05$

- Ultrasonography also has a significant role in differentiation of cases of cellulitis from abscesses as $\mathrm{Z}$ value is statistically significant, i.e., 2.58.

- Although ultrasonographic evaluation cannot replace clinical and histopathological procedure in the evaluation of various types of head and neck swellings, it plays a definite role as an adjunct to clinical evaluation of head and neck swellings.

\section{REFERENCES}

1. Rammohan C. Ultrasound unlimited - The A to Z ultrasound. 1st ed. Hyderabad: Paras Medical Publisher; 2005.
2. Palmer PES, editor. Manual of diagnostic Ultrasound. New millennium ed. Geneva: World Health Organization, New Delhi: AITB'S Publishers and Distributors.

3. Chodosh PL, Silbey R, Oen KT. Diagnostic use of ultrasound in diseases of head and neck. Laryngoscope 1980 May;90 (5 Pt 1):814-820.

4. Shimizu M, Ussmüller J, Hartwein J, Donath K. A comparative study of sonographic and histopathologic findings of tumors lesions in the parotid gland. Oral Surg Oral Med Oral Pathol Oral Radiol Endod 1999 Dec;88(6):723-737.

5. Siegert R. Ultrasonography of inflammatory soft tissue swellings of the head and neck. J Oral Maxillofac Surg 1987 Oct; $45(10): 842-846$.

6. Ishikawa $\mathrm{H}$, Ishii $\mathrm{Y}$, Ono $\mathrm{T}$, Makimoto $\mathrm{K}$, Yamamoto $\mathrm{K}$, Torizuka K. Evaluation of gray-scale ultrasonography in the investigation of oral and neck mass lesions. J Oral Maxillofac Surg 1983 Dec;41(12):775-781.

7. Das S. A manual on clinical surgery. 3rd ed. Calcutta, India: Dr. S. Das; 1988.

8. Pal US, Singh RK, Mohammad S, Gaur S, Dhasmana S. Ultrasonography: as diagnostic aids in the space infection. J Maxillofac Oral Surg 2006;5:8-12.

9. Sivarajasingam V, Sharma V, Crean SJ, Shepherd JP. Ultrasound-guided needle aspiration of lateral masticator space abscess. Oral Surg Oral Med Oral Pathol Oral Radiol Endod 1999 Nov;88(5):616-619.

10. Baurmash HD. Ultrasonography in the diagnosis and treatment of facial abscesses. J Oral Maxillofac Surg 1999 May;57(5):635-636.

11. Howlett DC. Pictorial review - high resolution ultrasound assessment of parotid grand. Br J Radiol 2003 Apr;76(904): 271-277.

12. Alyas F, Lewis K, Williams M, Moody AB, Wong KT, Ahuja AT, Howlett DC. Diseases of submandibular gland as demonstrated using high resolution ultrasound. Br J Radiol 2005 Apr;78(928):362-369.

13. Howlett DC, Alyas F, Wong KT, Lewis K, Williams M, Moody AB, Ahuja AT. Sonographic assessment of submandibular space. Clin Radiol 2004 Dec;59(12):1070-1078.

14. Traxler M, Schurawitzki H, Ulm C, Solar P, Blahout R, Piehslinger E, Schadlbauer E. Sonography of non-neoplastic disorders of salivary glands. Int J Oral Maxillofac Surg 1992 Dec;21(6):360-363.

15. Schemelzeisen R, Milbradt H, Reimer P, Gratz P, Wittekind C. Sonography and scintigraphy in the diagnosis of disease of major salivary glands. J Oral Maxillofac Surg 1991 Aug; 49(8):798-803.

16. Yoshimura $Y$, Inoue $Y$, Odagawa T. Sonographic examination of sialolithiasis. J Oral Maxillofac Surg 1989 Sep;47(9): 907-912.

17. El-Silimy O, Corney C. Radiology in focus: the value of sonography in management of cystic neck lesions. J Laryangol Otol 1993 Mar;107(3):245-251. 